\title{
Five Decades of Structure: A Retrospective View ${ }^{*}$
}

\author{
Juan V. MAYORAL
}

Received: 18.6.2012

Final version: 30.7 .2012

BIBLID [0495-4548 (2012) 27: 75; pp. 261-280]

ABSTRACT: This paper is an introduction to the special issue commemorating the 50th anniversary of the publication of The Structure of Scientific Revolutions by Thomas Kuhn. It introduces some main ideas of Structure, as its change in historical perspective for the interpretation of scientific progress, the role and nature of scientific communities, the incommensurability concept, or the new-world problem, and summarizes some philosophical reactions. After this introduction, the special issue includes papers by Alexander Bird, Paul Hoyningen-Huene and George Reisch on different aspects of Kuhn's work.

Keywords: Kuhn; structure; paradigms; normal science; scientific revolutions.

RESUMEN: Este artículo es una introducción al número monográfico que conmemora el $50^{\circ}$ aniversario de la publicación de La estructura de las revoluciones científicas de Thomas Kuhn. En la introducción se presentan algunas de las ideas principales del libro, como su cambio de perspectiva histórica para la interpretación del progreso científico, el papel y naturaleza de las comunidades científicas, el concepto de inconmensurabilidad o el problema del cambio de mundo, y se resumen algunas reacciones filosóficas a las mismas. Tras la introducción, el número monográfico está compuesto por artículos de Alexander Bird, Paul Hoyningen-Huene y George Reisch que versan sobre diversos aspectos de la obra de Kuhn.

Palabras clave: Kuhn; estructura; paradigmas; ciencia normal; revoluciones científicas.

\section{Introduction}

The Structure of Scientific Revolutions ranks high among the most significant books in twentieth-century philosophy of science. Its influence has been much broader, though. Thomas Kuhn's ideas, as they appear in that book, have influenced many reflections about the relation between science and society, science and religion, science and politics, and many other conjunctions of "science and ..." that could come to our minds. Even its detractors (and there is an ever growing number of them) seem to have been affected by Kuhn's compelling points about how scientific communities (may) produce scientific knowledge.

In this Special Issue, three renowned Kuhn scholars-Alexander Bird, Paul Hoyningen-Huene and George Reisch-explore key ideas in the book, and some influences in modern culture, even outside philosophy of science itself (that is the case, for instance, of Reisch's paper). Their contributions are meant to inspire further reflections on the impact of Structure now that fifty years have passed since it was first published. However, before entering their discussions, a brief introduction to Structure, its main argument, and the criticism it has motivated seems appropriate. A retrospec-

* I wish to thank Alexander Bird, Paul Hoyningen-Huene and George Reisch their contribution to this Special Issue of Theoria. I am very grateful to the editors of Theoria (and to David Teira in particular) for their collaboration in this task, and to Steve Fuller, José Luis López, George Reisch (once again) and Carlos Solís for their kind help with this introduction. 
tive view, in short, is in order. I shall try to provide the reader with it in the ensuing introduction.

\section{A Pattern for History}

"This is an important book"- that was Mary Hesse's diagnosis in reviewing Structure (Hesse 1963, 286). Kuhn, she added, had "assembled from various quarters truisms which previously did not quite fit and exhibited them in a new pattern in terms of which our whole image is transformed". Hesse's words are truly accurate. If we take a look to previous criticism of the positivistic tradition, we see that the history of science and psychology had already been useful in challenging the epistemological basis of its methodology. Actually, Kuhn framed some of his own views in an already established historiographical tradition, typically neo-Kantian, encompassing works by, e.g., Alexander Koyré and Emile Meyerson (see, e.g., SSR, viii; ET, xv, 11; Friedman 2003, 29; Gutting 2003; Larvor 2003). The same applies to, e.g., W. Köhler and K. Koffka's psychological criticism of philosophical epistemology, which paves the way to the naturalistic rephrasing of perceptual experience that Kuhn displays in Structure (see, esp., Koffka 1935).

I shall not examine Kuhn's predecessors and sources here. Rather, I shall assume what Hesse claims in her review, namely that one can find many ideas typically ascribed to Kuhn and Structure in well-known scholarly work, either in the philosophical field (Stephen Toulmin [1953; 1961] and N. Russell Hanson [1958] are a case in point), or in non-philosophical research (again, recall Koyré), and shall emphasise what Hesse says, namely that the book's main contribution is definitely the historical pattern it draws, i.e. the developmental framework it conveys. What elements could we discern in that pattern? I shall highlight three of them.

A first element is the significance of a historical perspective in constructing our view of rationality. Kuhn's position in Structure leads him to break up with a traditional uniformitarian perspective in the philosophical depiction of scientific rationality. This uniformitarianism is visible, for instance, in Karl Popper's perspective on rationality and method, in C. G. Hempel's view on scientific method (even as applied to history itself), and also in some modern accounts of David Hume's view of the constancy of human nature and consciousness through history, which, according to an interpretation (Pompa 1990, 12-16, 42-50), supports the idea that historical contingencies do not affect a core of dispositions, beliefs and rules. Certainly, Kuhn's view is more restricted in scope than Hume's, because he is not suggesting an alternative theory of human nature. Still, Kuhn claims that criteria composing a theory of scientific rationality-whether rules or, Kuhn's preferred alternative, values-are not constant throughout history. They change over time, particularly when a scientific revolution occurs. On that account, even though, as Hume says, evidence preserves a causal role in the production of certain inferences leading to knowledge, claims concerning the inferences (to be) used, the assumptions considered legitimate, and the role evidence plays in them are not historically invariable facts. In other words, for Kuhn the elements of rationality are not combined in the same way in every epoch of the history of science. So, if Hume, as seen in this way, is a recognisable predecessor of an empiricist 
uniformitarian anti-historicism (as, e.g., Hempel's and Popper's), then Kuhn is clearly arguing against him and the tradition that followed.

A second element is the revision of our conception of scientific revolutions, as far as the notion itself has its own history (see Cohen 1985). This revision starts from the idea that there already is a previous historical pattern in that uniformitarian viewpoint. That pattern, though, is hidden because of two facts: (1) scientific disciplines redescribe their own history as they are given birth after a scientific revolution; (2) any theoretical, observational or methodological element that does not contribute to the current state of science they represent gets lost in redescription. After a revolution, a scientist is like-in Kuhn's words-"the typical character of Orwell's 1984, the victim of a history rewritten by the powers that be" (SSR, 167; see also its entire sec. XI). The resulting pattern is always that of a uniform contribution to the current state of knowledge-an "Orwellian redescription" actually. This picture of history and its historiography is known as "Whig history", against which Kuhn sets himself-although, as in other cases, he seeks support in historians like, e.g., H. Butterfield (1931; 1949), or Koyré (see Larvor 2003). ${ }^{1}$

Finally, a third element is the historical pattern itself, and the explanation of scientific change it provides. Certainly, Kuhn's alternative to the uniformitarian and Whig view of scientific development embraces the idea of a scientific revolution as characterised by premises (1) and (2) in the paragraph above, but his theory is more complicated than that Orwellian redescription. Kuhn's pattern is not based on the "end points" of research-i.e. those theories or theoretical statements that are deemed true-as explanatory elements in his account of scientific development. In some passages of his writings, whether Structure or not, Kuhn seems to be using that recourse; e.g., when he said that "Energy is conserved; nature behaves that way" (ET, 72). However, in this case Kuhn argues that, even though that fact explains why the elements that compound the simultaneous discovery of energy conservation "were there" [sic], the historian of science does not know how they "suddenly became accessible and recognizable" $(E T, 72) .^{2}$ For him, the, as it were, "final point" of a given

${ }^{1}$ There is evidence, however, that Kuhn's anti-Whiggism is previous to any contact with the history of science-including Butterfield's writings. See Mayoral (2009, sec. 2). On the historiography of scientific revolution, see Beltrán (1995) and Mayer (2000; 2004).

${ }^{2}$ In his commentary on Kuhn's (1959) paper, the historian Carl B. Boyer (1959) criticised what he considered a problematic statement ("Energy is conserved; nature behaves that way"). That statement, Boyer says, "seems to imply a notion of energy as something actually in nature which we discover, rather than as a concept which we invent as one appropriate means of describing nature" (Boyer 1959, 385). Boyer points out, in other words, that even though Kuhn seems to be analysing "discovery" in less than Whiggish terms, he is not completely anti-Whig. I think Boyer's point pertinent, but I also think that it is difficult to block out the subsequent history of a scientific discovery and that historythat "life"-is the subject of the historian's research. Let's take into account, for example, that even phlogiston was once "discovered", and, for a considerably long time, it was a successful recourse. If so, for a historian of science in mid-eighteenth century, wondering what did lead to phlogiston (as a fact of the matter) would not be considered a wrong beginning. The question whether phlogiston and energy exist or not-and in what sense we accept the resulting conclusion, whatsoever-is matter for a realist and anti-realist philosopher to decide. Meanwhile, it is legitimate to narrate the discovery of 
body of knowledge does not explain what has driven experts up to that point. The fact making a certain statement true does not explain—or, at least, not completely—how scientists, organised in a certain way (and organisation is important-more on this below, sec. 5), got to combine the semantic and cognitive categories and the instrumental tools required to describe the phenomenon in question and to find out if it is true or false. In Kuhn's perspective, it is rather what takes place during the transition from some "end point" to the next that gives shape to, properly speaking, an explanation of the progress of scientific knowledge, including discoveries of novel facts. Kuhn rules out the idea of scientific discovery as a new simple and monolithic fact (or novelty) an individual scientist unearths by herself. Scientific progress and discovery, at large, require a more sophisticated explanation than that. Structure provided a first glimpse of the kind of explanation required.

If a number of scientific revolutions have happened all over the history of science, and if all of them involve a redescription of the previous history, then the historian of science's main task is not descriptive, but rather critical. She should focus on distinguishing what has been "scientific", even though it could be hidden under the history written after a scientific revolution (i.e. redescribed at that point) as "unscientific". End points-i.e., scientific novelties or discoveries, for short-will not do if that critical task is to be done. Thus, Kuhn's perspective referred to above imposes itself. The question now is what happens before and after the emergence of scientific novelties; or, in other words, what comes in between two successive scientific revolutions? Structure suggested an answer to this urgent question.

\section{In the Kingdom of Means}

If Kuhn pioneered the idea that causes explaining scientific advancement cannot be final, then he had to point out what other causes we should pick out instead. We can understand Kuhn's answer to this requirement by interpreting it from an axiological point of view as follows.

For Kuhn, the search for theoretical truth is a basic requirement for every one engaged in a scientific career. As he says in Structure, a high-level commitment for the practising scientist is the concern "to understand the world and to extend the precision and scope with which it has been ordered", something leading to "scrutinize ... some aspect of nature in great empirical detail". However, the scientist may realise that what the situation actually requires is "a new refinement of his observational techniques or ... a further articulation of his theories" (SSR, 42). Some recent supporters of scientific realism have resolved that theoretical truth is just a regulatory ideal, whose realisation can at best only be understood as an inference to the best expla-

phlogiston, or of energy conservation; even more so if we assume — as Kuhn invites to do- that scientific discovery is a process that involves a change of language and world-view, and sometimes social and institutional transformations. Blocking out phlogiston or energy as realistic assumptions that have no place in historiography leads us to a sort of historiographical quietism - and, the worst, because of hidden realistic assumptions. In my view, this is a common misunderstanding of Kuhn's anti-Whig convictions. On Kuhn's anti-Whiggism, see Hoyningen-Huene's contribution to this Special Issue, below. 
nation at the meta-methodological level. ${ }^{3}$ Kuhn would agree with the first part of that claim: the search for theoretical truth is, at best, a regulatory ideal widely spread all over the scientific profession-it is something "without which no man is a scientist", as he says $(S S R, 42)$. However, what leads the scientist to her professional goals is rather a set of lower-level commitments, whose relative priority depends on the particular state of the discipline in which she is immersed. Sometimes-and depending on the group she is working for-the state of the discipline will require her to contribute for the theory or method in question to gain precision or scope. Sometimes, though, she will have to reformulate the theory in, e.g., a more powerful mathematical language (see SSR, esp. 23-33, for some examples of these different kinds of research). Ends inspiring these kinds of work no longer simply amount to the search for theoretical truth, but rather to some more specific goals whose realisation is more likely to be perceived.

By alluding to these lower-level aims, Kuhn would be able to explain, prima facie, how Orwellian redescriptions emerge. However, this would not lead to a truly Kuhnian perspective on the progress of science in the sense I am interpreting it here, because final causes would have not been left aside. In fact, Kuhn does not base his perspective on these kind of values. Rather, they are a sort of spin-off of his more fundamental critique of the theories of scientific development. This critique involves reconstructing the agent's point of view as that of an individual who learns and improves an overall perspective on the world and a language that, in principle, are only valid within a closed community. In this situation, the appeal to values is uncommon. It is more frequent when it comes to an extraordinary-science situation-or to science in crisis. Even so, Kuhn says, appeal to values remains idiosyncratic, and sometimes factors influencing theory choice are not strictly scientific (SSR, 152-153). All this does not mean that science is in Kuhn subjective and irrational-as D. Shapere (1964, 1966, 1971), or I. Sheffler (1982) said. (See Kuhn's reply in SSR, 185-186; ET, ch. 13.) It does not mean that normative perspectives on rational theory choice are not available in Kuhn's theory, either (see Hempel 1979, 1981, 1983a, 1983b, Kuhn 1983, and Salmon 1983), because he can clearly show when a certain theory choice is rational and when it is not. ${ }^{4}$ It is just that Kuhn's account of rational theory choice does not rely on a simple, context-independent set of quasi-algorithmic rules. Normativity is rather imposed by a language and the "rules" (or rather, the implicit guidelines) for using it. Saying that a scientist has made a theory choice on the basis of some values

${ }^{3}$ An account of the realistic point of view concerning truth can be found in Sankey (2008, ch. 6, and esp. 96-107) and Psillos (1999, ch. 4). A contrary position is available in Laudan (1984, 1996, esp. ch. 7). As it is well known, scientific realism is rather a family of disciplines and its relation to theoretical truth is currently a much-disputed issue. So we must take these references as merely representative of a high (and increasingly growing) number of works. Sankey (2008, ch. 1) is a careful and informative introduction to that family, and further chapters in the same text connects that trend to issues in Kuhn's philosophy of science.

${ }^{4}$ Kuhn's view on theory choice and its rationality remains for many an open issue as yet. See Nola and Sankey (2007, 45-49, 86, 99-100, 236-239, 285-298) and Salmon (2005, ch. 6). 
(and not others) amounts to speaking about an orthodox behaviour according to a paradigm-based language (or theory).

So we could say that values supervene on a certain kind of practice as the goals that seem to be realised if that practice is deemed satisfactory by the practicing subjects. Of course, this point of view does not exclude that a final goal of gaining theoretical truth is ultimately satisfied; and it definitely does not involve, either, that that highest-level alethic goal is ultimately unsatisfiable. This option between a realistic and an anti-realistic approach to scientific knowledge remains open at this pointalthough maybe not beyond this point. Yet, that goal, theoretical truth (and just like other, lower-level ones), does not function as a (final) cause of progress. "(Being, or becoming) scientific" is thus not a matter of fulfilling rules-as methodological imperatives - every scientist learns from her earliest moments in the profession. It rather consists in something more similar to behaving and speaking correctly within a scientific community.

How a social behaviour is scientific in this sense and in absence of continuously working rules of scientific method is part of the description that mainly occupies Kuhn in Structure. Kuhn describes it in the first sections of the book devoted to depict normal science-i.e., secs. II-V—and also in the following sections, where he displays two less common situations: science in crisis and extraordinary science. Secs. VI-IX deal with this latter situation in more detail. Whatever the situation, however, Kuhn focuses on describing the generalised efforts of every member within a community to get the theory closer to the world and vice versa. Of course, such words as "theory" and "the world" get through a semantic transformation with regard to previous meanings in Kuhn's theory (more on this below, sec. 6). Even so, that would be a good description of the way an average scientist would see her own practice- even though, in the renewed terms of Structure, it would be expressed rather differently, as, e.g., pursuing the "articulation of a paradigm" or "extending the scope and/or the precision of a paradigm". Structure shows how these more modest activities take place in scientific research on a daily basis, and represent a high percentage of normal activities in science.

It should be emphasised that that image of scientific activity is akin to an intentional explanation from an individual point of view. For example, we could explain the sort of activities we call normal science as the individual search for coherence within the world picture she has been led to by means of her scientific training. Kuhn, however, did not proceed this way. In Structure we find a sort of historical and anthropological description of research activities within a scientific community, likely intention-

\footnotetext{
${ }^{5}$ Moreover, not only truth does not explain anything by itself-it cannot be the subject of our explanation, either, because we cannot make sense of the expression "achieving the truth" in a non-circular way. That is why anti-realism is ultimately Kuhn's explicit position, as he shows in a later paper: "I must first ask what it is that still requires explanation. Not that scientists discover the truth about nature, nor that they approach ever closer to the truth. Unless, as one of my critics suggests [Hawkins 1963], we simply define the approach to truth as the result of what scientists do, we cannot recognize progress towards that goal. Rather we must explain why science-our surest example of sound knowledge-progresses as it does, and we must first find out how, in fact, it does progress". (1970, 20; ET, 288-289.)
} 
al explanations of that behaviour being left aside. This is something we can find in Kuhn's previous - though unpublished-writings as, for instance, his Lowell Lectures (Kuhn 1951, esp. lects. V-VI; see SSR, ix), where he accounts for the emergence of problem solutions through a change in the viewpoint, which is explained in turn by positing a phenomenological world that echoes Kurt Koffka's "behavioural worlds" (Koffka 1935, 31; see also Marcum 2005, 33). This resource (and the corresponding intentional explanation) is avoided in Structure, thereby skipping a teleological account of scientific behaviour once again. This latter is described in terms of a research behaviour characterised by the emergence of a key exemplar, the paradigm, which serves as an inspiring model of solved problem, around which a theory or a group of interrelated theories are erected. In short, even though previous writings attempted at an intentional explanation of scientific behaviour, Structure pursues instead a social description of scientific behaviour.

As seen in this way, Kuhn's perspective can show what lies behind the Orwellian redescription of the history of science that takes place during and after a scientific revolution. By exploring the scientific behaviour in terms of the recognisable activities that an informed reporter (as himself) can observe, Kuhn constructs a social description that shows that scientific research is organised around the enhancement of a point of view marked out by a paradigm and the disciplinary resources surrounding it. No goals determine scientific behaviour, but rather a seemingly well-arranged social activity of research. Scientific revolutions signal the split with ordered research around a certain paradigm and the emergence of an alternative. States of crisis are also accounted for as stages with a prevailing atmosphere of uncertainty, when the potential of a paradigm to draw together dispersed research seems exhausted, and different groups (or schools) look for their own guide. In a nutshell, all that happens in between scientific revolutions explains them, whereas the breakthroughs achieved in theme.g., discoveries - cannot count as final causes of the progress they represent. Kuhn's theory shows by way of historical criticism how the very same version that accounts for the justification of scientific knowledge and offers some prospects of defining a demarcation criterion is simultaneously unable to explain properly how scientific knowledge is achieved.

\section{Understanding Normal Science}

Structure was a success from the outset. 1900 copies had been sold by February 1963, when the University of Chicago Press started to plan a reprint. ${ }^{6}$ Kuhn had made efforts in order to get the book out of the International Encyclopedia of Unified Science, (for whose second volume it had been commissioned) as also a separate volume (RSS, 300-301). The press conceded this request. But he was nonetheless concerned about the reception. In the first place, he was afraid of a very modest acquaintance with it by

\footnotetext{
${ }^{6}$ See I. Jefferson's (18 Mar. 1963) and J. H. Storm's (21 Mar. 1963) letters to Kuhn, TSKP 25.55. According to the University of Chicago Press, almost half a million of copies of the original book (different editions) had been sold by 2003, and it has been translated to 33 languages (these facts are taken from Solís 2006, p. 32, n. 21).
} 
the academy. In the second place, he wished for a good reception on the part of the philosophers of science (RSS, 306-307). Actually, as J. W. N. Watkins recalled few years later, in 1963 the book had already been "discussed at length at Sir Karl Popper's seminar, where Mr Hattiangadi gave a paper on it (which he afterwards expanded into a ... dissertation)" (Watkins 1970, 25). In short, the year following its publication, the book had sold well, and some philosophers of science were discussing its contents in detail. That was just the beginning.

A wide reception does not entail a positive reaction. For supporters of Popper's critical rationalism as Watkins and I. Lakatos, it was not easy to admit Kuhn's emphasis on normal science. Watkins made it clear as follows:

Why has Kuhn, despite his concern "with the dynamic process by which scientific knowledge is acquired" [Kuhn 1970, 1; ET, 267], come to identify science with its periods of theoretical stagnation? ... why has the author of one excellent book on the Copernican revolution [Kuhn 1957], and of another more famous book on scientific revolutions generally [SSR], taken a sort of philosophical dislike to scientific revolutions? Why is he so enamoured with plodding, uncritical, Normal Science? (Watkins 1970, 32.)

Though Watkins is distorting Kuhn's actual message-it is difficult to grasp any "philosophical dislike to scientific revolutions" in Kuhn's writings whatsoever-he is nonetheless illustrating a popular reaction to normal science among many readers of Structure, Popper's disciples included.

To tell the truth, normal science is difficult to accept. For some persons, an effort is needed in order to avoid undesirable implications, particularly those that verge on relativism and irrationalism. However, normal science, as described in Structure, reveals that science is a collaborative enterprise in which some likely results are considered as matters of fact and what is really in question is who is going to be the individual (or group) achieving those results. As Kuhn says in his 1965 paper for the London Colloquium at the Bedford College: "In short, though tests occur frequently in normal science, these tests are of a peculiar sort, for ... it is the individual scientist rather than current theory which is tested" $(1970,5 ; E T, 271)$. Criticism is, therefore, strategically set aside for a while in order to, first, be successful in gaining a high status within a scientific community - Kuhn shows that personal decisions in that sense have epistemic consequences, and not by accident. Second, criticism is also avoided in order to make a change in the current status of the theory that the researcher has been led into (a change for good the researcher and the rest of the community are confident that can be made).

Structure does not say that science cannot be practised in any other way. It just describes the historical pattern of a class of scientific disciplines that fits that strategic way of cooperation and dogmatic behaviour, which matches up with the most advanced (i.e. successful) ones. Certainly, the term "dogma" is anathema to those who pursue a demarcation criterion on the basis of critical rationalism. For good or ill, that basis attracted many readers' attention (and contempt) to this particular aspect of normal science-dogmatism. Yet, if we carefully distinguish the socio-historical discourse in virtue of which normal science and paradigms are introduced in the first sections of Structure from the cognitive view required to explain paradigm-based research, we see that there is room for that kind of dogma without affecting the normative assump- 
tions about a rationally constructed view of science. Admittedly, Kuhn's way of distinguishing those kinds of discourse in Structure was not crystal clear-he tried to fix it in later writings and lecture series. But we can draw the divide ourselves if we try.

So, let us try. First, there are two main ways in which paradigm-based research can be introduced: (1) by means of a series of examples, which are supposed to be general enough, or (2) by means of an epistemological theory that explains rules away in virtue of some theory of human cognition that privileges paradigm-based research to the detriment of a rule-based one. In Kuhn's case, normal science and paradigm-based research is mainly introduced in Structure in the first fashion, whereas its cognitive consequences-which would need an explanation in the second sense-are mostly consigned to section X, only. Now, paradigm-based research leads to some striking scientific behaviour: scientists do not react to counterinstances and anomalies as expected. They remain plainly conservative, and they prefer to employ their time in solvable problems. Their behaviour is, therefore, seemingly dogmatic, which seems to be a counterexample to the hegemonic methodological theory; ${ }^{7}$ even more so if we take into account that this kind of dogmatism leads, according to Kuhn, to a very productive pattern of inquiry.

That seemingly unexplainable and unreasonable dogmatism leads us to question whether paradigm-based research is rational. By adopting a cognitive point of viewinstead of the socio-historical approach that pervades Structure - that kind of dogmatism looks rational. From that point of view, there is not-to use Kuhn's words (SSR, 114) —any "higher authority" for a scientist other than her own epistemic categories and the semantic system she uses to describe the world out there. Kuhn does not devote space in Structure to specifically account for the structure of human cognition and communication that his own theory requires. That would have been important, though, because doubts about the rationality of a seemingly dogmatic view in this context tend to disappear as soon as the individual point of view is studied in depth. ${ }^{8}$ For instance, when the scientist finds a divergence in results with regard to expectations, she also runs into an obstacle—she has to prove oneself and the others that, e.g., that divergence is a counterinstance to her pet theory (i.e., that she has truly bumped into a genuine anomaly in her assumed, learned theoretical world). If there is no higher authority to rely on in that case, many alternative explanations of the divergence should be explored and excluded-for example, that she has found an unexpected consequence of her pet theory, or (worse) that the experimental device does not work well, or (still worse) that she has not performed the experiment correctly. Even if we assume that the divergence reflects a true anomaly, the scientist still requires a further paradigm in order to properly formulate the nature of the anomaly as the discovery of a new sort of phenomenon. Methodological conservatism and dogmatism is, as seen

\footnotetext{
${ }^{7}$ For Kuhn, however, these counterexamples will be tautologies when approached from the new epistemological theory he advocates. See SSR, pp. 77-78.

${ }^{8}$ Bird criticises how scarce is Kuhn's engagement with this matter in Structure and later writings, and how promising is, in contrast, this cognitive approach for science studies. See his contribution to this Special Issue, below.
} 
in this way, a rational behaviour (see Quine and Ullian 1978, ch. 6, for further support on this methodological position). Structure would have benefited from a theory of human cognition explaining this situation in detail, a theory showing how a dogmatic behaviour is comparatively more rational than a permanent search for criticism and alternatives - something more akin to Popper's and P. K. Feyerabend's positions, respectively. Indeed, dogmatism in Structure is defensible from that point of view.

However, a cognitive theory of that kind is, as noted, wanting in Structure. Besides that, some of Kuhn's expressions there do not help much, either. The idea, for instance, that the pattern of scientific practice leading to maturity and productive results is mostly composed of "mopping-up operations" (SSR, 24) surely helped to keep more heroic depictions of scientific research away-like, e.g., the Popperian account of typically rational, properly scientific behaviour. In absence of the proper supporting theory, however, eschewing the rationalistic account of behaviour, even as naïve as it sounds, produced an undesirable result for Kuhn: Structure was considered a manifesto for subjectivism, irrationalism and relativism in the philosophical image of science, something totally contrary to his author's point of view (which, at the end of the day, was that of a former theoretical physicist). As he remembers, "Students used to come to me saying things like 'thank you for telling us about paradigms—now that we know what they are we can get along without them'.... That wasn't my point at all'. (RSS, $308)$.

\section{The Closed Society}

In his 1995 interview (RSS, pt. 3) Kuhn recalls that once in a Princeton seminar some student told the audience that: "You have to realize that in terms of what you are thinking of, this [i.e. Structure] is a profoundly conservative book". Kuhn went on reasserting: "And it is; I mean, in the sense that I was trying to explain how it could be that the most rigid of all disciplines, and in certain circumstances the most authoritarian, could also be the most creative of novelty" (RSS, 308; my italics). We should have in mind that previous accounts of scientific progress-Popper's included-sounded as chants of rationality within an open and equalitarian society. Even R. K. Merton's sociological "ethos of science" (Merton 1942) fits in that picture of society squarely. Kuhn showed instead that the locus of science is not society at large- science is not public. The scientist is, first and foremost, a member of a relevant group of researchers. For someone to become a member of one of these groups a substantial amount of training is required. This training includes adopting a sort of "second nature" (as Bird says) that influences paradigm-based thinking (see Bird 2002, 450; 2008, 26), an often difficult and always highly idiosyncratic language, and a great deal of hands-on experience. Thus trained, the scientist assumes the problems the community as a whole considers solvable and more pressing, and, as noted, only her competence might be in question. Once she has accepted the challenge, she does not work alone any longershe works as part of a "cell", the scientific community. This is the minimum epistemic unit (or agent) that trades in knowledge with society at large.

So, for Kuhn, scientific knowledge is owned by society only at a price, namely that, as regards production, improvement and usage, the agent is no longer the individual, 
but rather a group, a collective-to wit, in Kuhn, the scientific community. More importantly, the community is an agent that reserves the right to refuse admission. Thus, in Kuhn's theory scientific knowledge is an epistemic tool whose rationality could be (as ever) in doubt. Yet, resolving this doubt is no longer accessible to everyone; after all, the public has news about scientific knowledge only through that restricted circle of producers and owners, the scientific community, which in Kuhn's picture is that sort of "closed society" (I borrow that phrase from Watkins 1970, 26). Criticism of scientific knowledge is thus pointless if it is not well informed. But as soon as the individual is trained in the discipline in question, her ability to criticise diminishes as well. If scientific knowledge is granted to the public by means of this structure of closed societies, the price may be too high. Steve Fuller (2000; 2003) criticised these consequences of Kuhn's theory, and pointed out some of its likely political and ideological sources (see also Reisch's contribution to this Issue, below).

Another consequence Kuhn introduced in Structure was even less admissible by philosophers of science-incommensurability. Kuhn introduced the term in Structure after showing by way of example that the change of meaning after a paradigm shift turns the theory emerging from a scientific revolution "not only incompatible but often actually incommensurable with that which has gone before" (SSR, 103). As far as I can tell, the term in question is mentioned for the first time in a private notebook Kuhn started in 1949, as a junior fellow of the Society of Fellows (Kuhn 1949, 24), when reading a book by the psychologist $\mathrm{H}$. Werner (1948), in order to refer to that effect of lack of common measure between kinds of motion in Aristotle's physics. Like the term "paradigm", which is also visible in his Lowell Lectures (Kuhn 1951, V, 45; VI, 1) in its usual, psychological sense, incommensurability turned out to be something else in Structure.

That change of meaning was radical, indeed. In Structure, incommensurability was used after showing that the logico-positivistic account of inter-theoretical reduction, a common example of which was the reduction of Newtonian to relativistic dynamics, was faulty. Allegedly, in making the Newtonian theory derivable from relativity theory, the former could be explained in relativist terms (SSR, 101-102). To do so, however, definitions of variables must be changed, so "derivation" is not, properly speaking, the result of inter-theoretical reduction, but rather a sort of relativistic explanation of Newtonian dynamics, which had long left Newton's theory behind. Both theories, Kuhn concluded, were actually mutually incommensurable. If we wish to avoid this consequence, we have to restrict the meaning of terms in our pet theory (e.g., in Newton's theory). But Kuhn insisted since at least 1951 (see his last Lowell Lecture) that to do so the "range of application [of a theory] must be restricted to those phenomena and to that precision of observation with which the experimental evidence in hand already deals" (SSR, 100). The problem is that the theory would thus be prohibited from any area to which it has not been previously applied. This procedure sets a limit to the exploration of novelty; it prevents scientists even from relying on a theory in their own research if it "enters an area ... for which past practice with the theory offers no precedent" (SSR, 100). In short, for Kuhn, the same strategy that helps logical positivism to save some theories from sinking into oblivion renders scientific research 
unable to progress. Ironically, incommensurability is thus rendered as the consequence of a kind of language that can deal with unexpected novelty. ${ }^{9}$

That is the language of Kuhn's closed societies. Three of its properties are clear: (1) only experts know how to use scientific language properly; (2) however, experts in different stages of the history of science may have troubles in making it clear what other "speakers" tell about the world (e.g., individuals practising science before the latest scientific revolution); (3) all efforts to limit referential capacities of these languages to what is already known can result in undermining their heuristic power. In other words, rational reconstruction and the ability to face novelty are incompatible strategies.

It is no wonder Kuhn's historical pattern of scientific development, with its epistemic and semantic analysis in terms of a structure of closed groups (instead of the former unified society of individuals) and their languages, was hard to accept. Old venerable hopes of universality of language, of simple additivity of scientific results, of absence of barriers to human understanding - all these assumed characteristics of scientific rationality were boldly dismissed in Structure in order to construct an alternative view into the cooperative enterprise dealing with novelty, and the language that makes that cooperation possible (or at least to suggest how it should be done). The question is whether these old venerable hopes could really be dismissed by the sort of perspective that Kuhn articulated in Structure. Actually, it did not seem like they could be dismissed, so Kuhn had to practice a more classic philosophical art in subsequent works, particularly in those published as an answer to his many critics in the early seventies, and later on during the eighties. The evolution of Kuhn's philosophy is marked out by his attempt to make his theory palatable to more traditionally inclined philosophical tastes. He gained acceptance among sociologists and socially inclined historians of science- the Strong Programme, in particular. ${ }^{10}$ His main goal, though, was to make his developmental turn in science studies possible among philosophers of science, the more traditional, the better.

\section{The Worlds We Live In}

Polemic as these ideas were, we should still take into account another radical thesis and the section of Structure containing it-section X. In that section, Kuhn talked about perception. Note that this is a book in which the practice of sciencesomething an external observer is entitled to experience and testify-is the main theme. However, as far as perception goes, we start requiring a different kind of report: those including information on inner states or representations. Particularly so, as far as Kuhn's aim is to show that a classic dogma of the inherited tradition, observation language, and the broader perspective embracing it (the empiricist one), must be

\footnotetext{
${ }^{9}$ See a classic discussion of this argument in Field (1973; 2001a). A thorough discussion of incommensurability can be found in Hoyningen-Huene (1993, 206-222), including an exhaustive list of references on the issue up to the nineties. See also Sankey (1994), Buchwald and Smith (2001), D'Agostino (2003), and, of course, Kuhn's second thoughts on incommensurability in RSS, chs. 2, 4, and Kuhn (1999).

${ }^{10}$ A good introduction to this connection is Solís (1994).
} 
abandoned. As we see in Structure, more than external reports are required to force that abandonment.

The section was important to Kuhn himself. Around a year before publishing the book, Kuhn told his mentor, James B. Conant, that that section was the most important in Structure. Section X dealt with paradigm-dependent perceptual experience; or, more properly, Kuhn tried to show how the contrary notion-paradigmindependent perceptual experience, and an antecedently fixed observation languagewas highly unlikely. Actually, the assumption that this contrary notion is possible is for Kuhn part of a tradition that went a long way back to the seventeenth century: a largely Cartesian tradition, whose sources were Johannes Kepler's studies on the eye and R. Descartes's mechanical explanation of vision. ${ }^{11}$ Kuhn had already shown in earlier sections of Structure that correcting observational expectations was key to, e.g., noticing anomalies (SSR, 62-65), so perception was a not-so-passive source of information for our mind. The paradigm-trained mind participates actively in moulding significant experience. As noted, even though Kuhn made this point clear, he was venturing into an entirely new ground. He started describing not how "paradigms are constitutive of science"- - taking science as an organised practice, as Structure shows-but rather how "they are constitutive of nature as well" (SSR, 110; my italics). Moreover, the new ground was highly problematic, because Kuhn not only wanted to say that the paradigmtrained mind interpreted a fixed world, but rather that the paradigm, literally, constituted the world. Solving this puzzle without assuming an extreme relativistic position was a challenge, indeed. The solution to this puzzle was to produce some argument in which the resulting picture displayed perception as paradigm-dependent, and the working assumption of a world outside our senses-i.e., a mind-independent world - was only taken, at best, as a causal substratum, our relation to which gets mediated through a historically changing set of categories. Not surprisingly, Kuhn's view recalls Kantian epistemology and metaphysics (although a bit revised). He famously said that he was a "Kantian with moveable categories" (see, e.g., RSS, 264), and his position should be taken as a "post-Darwinian Kantianism" (RSS, 104). Section X brought it forward. ${ }^{12}$

However, we should keep in mind what is involved in a Kantian approach like this. It involves metaphysical assumptions concerning the mind and its relation to the world, which allow us to draw epistemological conclusions concerning the justification of scientific beliefs. Was Kuhn ready to offer that kind of analysis in a book full of indirect arguments and "invitations" by counterexamples? Was Kuhn going to change his rhetoric in section $\mathrm{X}$ ?

Actually, he did not do it, so it will come as no surprise that many authors consider this section both the most thought-provoking in the whole book and, at the same

${ }^{11}$ For this historical connection and the previous statement on the importance of this section see Kuhn's letter to Conant, 29 Jun. 1961, TSKP 25.53, 5-6.

${ }^{12}$ To some extent, Kuhn's work has a family resemblance to C. I. Lewis's. This latter's influence on the former is visible in Kuhn's early musings on philosophy; see Mayoral (2009, 179-183). The connection Kuhn-Lewis has also been explored by Fuller (2000, pp. 266-280) and, more briefly, by Rosenthal $(2007,53)$. 
time, the most problematic one. Peter Godfrey-Smith (2003) is a good example of this. For him, "the book climaxes" in section X, where "Kuhn puts forward his more radical claims. Not only do ideas, standards, and ways of seeing change when paradigms change; in some sense the world changes as well" $(2003,96)$. Kuhn fills up the section with phrases expressing how a paradigm shift (which involves cognitive and ontological changes in the sense referred to above) brings along a new "form of life" entirely-my Wittgensteinian wink is not accidental, for sure. Kuhn put it in more familiar terms: after a scientific revolution has occurred, "the scientist afterward works in a different world" (SSR, 121). A number of similar passages occur in the same section, as follows (see a similar selection in Hacking 1993, 276):

Examining the record of past research from the vantage of contemporary historiography, the historian of science may be tempted to exclaim that when paradigms change, the world itself changes with them. (SSR, 111)

In so far as their only recourse to [the world of their research-engagement] is through what they see and do, we may want to say that after a revolution scientists are responding to a different world. (SSR, 111)

The very ease and rapidity with which astronomers saw new things when looking at old objects with old instruments may make us wish to say that, after Copernicus, astronomers lived in a different world. (SSR, 117)

... as a result of discovering oxygen, Lavoisier saw nature differently. And in absence of some recourse to that hypothetical fixed nature that he "saw differently", the principle of economy will urge us to say that after discovering oxygen Lavoisier worked in a different world. (SSR, p. 118.)

That is the last of the senses in which we may want to say that after a revolution scientists work in a different world. (SSR, 135)

Again, Kuhn does not support this "Living-in-a-different-world talk" in a principled way. As in previous sections, he tries to induce a certain expression, sometimes merely finding additional support in some broad assumptions - as e.g. the "principle of economy" (see Godfrey-Smith's critical point on this issue [2003, 97]). Moreover, by using a series of indirect suggestions - "may be tempted to exclaim that...", "we may want to say that..." (twice), "may make us wish to say that...", and "will urge us to say that..."-Kuhn timidly points to a paradigm shift, this time in the epistemological tradition. In short, as in other parts of Structure, Kuhn is not arguing philosophically on the basis of any normative principle-although the "principle of economy" is conspicuously breaking that rule. Kuhn suggests some generalizations concerning scientific behaviour that invite us to accept that another view of perception and epistemology is not only possible, but also preferable. Yet, he does not explicitly say what alternatives he is pointing to. (This is the same problem that affects his defence of the rationality involved in a dogmatic behaviour; see above, sec. 4.)

However, the most questionable part of his point came with the ambiguous meaning of "world" in this section, with particular emphasis on the passage I mentioned first: the (in)famous statement "though the world does not change with a change of paradigm, the scientist afterward works in a different world" (SSR, 121). This is a problem inherited from the particular rhetoric and argumentation Kuhn has chosen here, in which the meaning and nature of some key notion-like "world"-are left for the reader to decide. Clearly, the meaning of "world" requires explanation, because, 
somehow, after assuming that the world is something fixed, it is altered after a revolution, too. Making sense of this is a difficult challenge, because "the world does not change" is stated in the first part of the statement. An epistemically relativistic solution would help to make the second part true ("the world has changed"). But it will not do, because our solution must meet the requirement that "the world does not change". So, either we conclude that Kuhn has simply made a logical mistake by making an analytically false claim, or else we take this to be poetic license so that some sense of "world" is here purely metaphorical. Excluding the first option, a literal meaning of the term "world" is not assumed in both parts of this conjunction. The remaining challenge is to clearing up what part is purely metaphorical and what part is not. ${ }^{13} \mathrm{An}$ swering it involves taking issues with an intriguing question, namely: what is the literal meaning of "world"? In other words, a corollary of proving that we can provide a positive answer to that dilemma is that we already have an answer to the latter question.

Some philosophers have attempted to answering that question. In 1993, for example, Paul Hoyningen-Huene and Ian Hacking met the challenge of this "new-world problem", as Hacking called it. Hoyningen-Huene (1993, esp. ch. 2) offered an epistemological solution to it that was based in turn on some explicit metaphysical assumptions, a combination that also reminds us of Kant's. Hoyningen-Huene showed that if we combined an ontology of stimuli and a plurality of "phenomenal worlds" we would make sense of Kuhn's statement. For one thing, the fixed world is a Kantian "world-in-itself" (1993, 35), i.e. a causal background. Some epistemological benefits follow from that assumption, because scientific statements, observation reports included, are justified on the basis of that fixed background, which helps to avoid epistemic relativism in turn. For another, paradigm-dependent categories are still active, and turn stimuli input into the objects compounding the phenomenal world, i.e., the cognitive source of our beliefs. There are as many of these phenomenal worlds as individuals, but all of them see and speak about the same aspects of the world within a given community, so their number is virtually that of scientific communities, not individuals. The perspective was phenomenalistic rather than realist, one that fit Kuhn's perspective very well. In addition, it saved incommensurability (and the rest of Kuhn's theory) from relativism. The result was highly satisfactory to Kuhn, who famously said that "No one, myself included, speaks with as much authority about the nature and development of my ideas" (1993, xi). From this point of view, the meaning of "world" should include both notions as opposite sides of the same coin. They cannot be separated and none of them exhausts the literal meaning of "world" by itself. ${ }^{14}$ On that account, the challenge is not the one referred to above. Rather, the challenge is to

13 Howard Sankey, for instance, argues that the expression "world-change" should be taken as a metaphor. Even though his point is different from the one I have just made, it is a good example of an answer to the challenge. See Sankey (1994, 152-153, 179-180, 187-190).

14 See Hoyningen-Huene (1993, ch. 2, esp. 36-39, 60-63) for further details about Kuhn's position and its development. 
change the language that needs a metaphorical sense-i.e. the language that leads us to the new-world problem.

Ian Hacking's (1993) solution to the new-world problem focused primarily on the ontological aspects of that problem. It is nominalistic and shows that a world of individuals is compatible with a changing world of natural (for Hacking, rather "scientific") kinds. Hacking provided Kuhn's mature view of scientific lexicons with a semantic reconstruction of the lexical structures he seemed to assume, which were altered in a way altogether compatible with Kuhn's linguistic account of incommensurability. Hacking's version, however, preserves the dichotomy Kuhn seems to criticize, so the literal meaning of "world" corresponds to a world of individuals, which are differently classified in scientific kinds after every scientific revolution. Kuhn (RSS, 229) did not agree with this nominalistic interpretation. ${ }^{15}$

Whatever the solution, however, Kuhn did not seem as much concerned with those specific points (at least in Structure) as with promoting a change in philosophical language and the epistemological tradition. Perhaps we should understand section X as a sort of reductio ad absurdum, in which the new-world problem, as stated there, closes the assumption that observational language is possible with a simultaneous assertion and denial of the same proposition. From this point of view, the new-world problem reveals that the language of the old epistemological tradition should be altered. If true, this interpretation indicates that, in forcing upon us the new-world problem, Kuhn is not only attacking the idea of a pure observation languagevoking a crisis in epistemology by way of a rhetoric device (a bright tactic on that account). In short, Kuhn is saying that, once we admit that any mature scientific language is "paradigm-dependent", a pure observation language is hard to support. In supporting it, we should explain natural-kind terms in absence of a paradigmdependent language, and the linguistic vehicle does not seem available. The language and world-view assuming that chimera of observation language must be changed, replaced by a new epistemological tradition and its linguistic vehicle.

As seen in this way, Kuhn's new-world problem is not a self-contradictory ontological claim. Rather, it leads to conclude that a expression like "the world" belongs to a philosophical tradition - the one Kuhn wants to tear down (classic empiricism and its modern versions) - that assumes that a part of the language is exclusively devoted to express the given aspects of our experience (see Quine 1953). Once Kuhn has shown that normal scientific behaviour requires a difference in sense for a key word in that traditional language- "world"-and that making that difference explicit leads us to conclude that either (i) a contradiction in terms obtains, or (ii) the simultaneous usage of a metaphorical and a literal meaning of the very same word is required to describe the same situation, he is also showing, as noted, that that language (or the epistemological paradigm on which it is based) ought to be abandoned. From this point of

\footnotetext{
${ }^{15}$ On Hoyningen-Huene's and Hacking's accounts of the new-world problem, see also Preston (2008, 73$75)$ and Gattei $(2008,131-133)$. Of course, there are alternative solutions to the new-world problem, e.g., that suggested by Fuller (2002, 87-89), who combines realism about possible worlds and antirealism about the fixed world.
} 
view, Kuhn is already acting as a linguistic philosopher. His most important section in Structure (i.e. sec. X) aimed at suppressing a convention of our language (i.e., that observation language is possible), and tried to provide an alternative-paradigm-dependent language and world (the very basis of his own later linguistic-relativity thesis).

\section{Fifty Years Later}

Let us summarise what we have seen so far. In Structure, Kuhn suggested that the uniformitarian view should be altered, that the danger of a blind dependence on an Orwellian redescription of the past was real, and that our view of scientific rationality required us to re-examine our well-established convictions on science. His historical pattern was designed to drive this re-examination. However difficult, the idea that a part of our society was closed and spoke its own language-a speech that changed over history - had to be considered. Dogmatism seemed to be involved, but Kuhn tried to show how it should be properly analysed in order to do without its irrationalistic sense. More difficult was to accept that the incommensurability of languages and scientific world-views should also be a part of our conception of science, as well as his attack on observational language and the entire tradition that assumed it. Kuhn tried all this on the basis of counter-examples and, as it were, poetic license. The problem with this style of arguing is that for many analytic philosophers Structure was (and still is) an impressionistic, but ill-designed, subjectivist manifesto: a short book prepared to attack positivistic viewpoints on science and rationality indiscriminately. In this short introduction I have tried to show that Structure was a much more sophisticated instrument of change. It was a monograph that consciously attempted to push a change forward by persuading the users of the tradition of the shortcomings of the categorical set they assumed.

Fifty years later, many issues remain open. The following papers shall discuss some of these issues. PAUL HOYNINGEN-HUENE's contribution studies the so-called "selectivity of historical judgement", which leads him to examine Kuhn's anti-Whig position in more detail. Hoyningen-Huene also explores some of Kuhn's assumptions in that sense- the rationality that results from that historical pattern, the kind of internal historiography he practiced, and his historical realism. His paper gives us an insight into Kuhn's anti-Whiggism. ALEXANDER BIRD gets deeper into his classic theses on Kuhn, as presented in some of his well known papers and in his book (see e.g. Bird 2000, 2002, 2005, 2008), namely the significance of Kuhn's naturalistic turn-against his later "wrong turn" to a more positivistic approach to science-and the greater importance of the concept of paradigm over Kuhn's preferred notion of incommensurability. Bird shall explore the cognitive approach to science studies from the point of view of a study of concepts, on the one hand, and a study of cognitive habits, on the other, and shall draw conclusion on which is more fundamental than the other. Last, but not least, GEORGE REISCH - who more than a decade ago showed that Kuhn had not "assassinated" the modern heirs of John Locke (see Reisch 1991)—examines Kuhn in the context of Cold-War culture and politics. Reisch argues that the role of dogma and theory choice as a "conversion experience" in Structure exemplifies Richard Hofstadter's "paranoid style", as connected to Cold-War themes and worries. Reisch 
explores Kuhn's personal connection to wartime and Cold-War administrator (in addition to Kuhn's mentor and sponsor) James B. Conant, and its intellectual consequences. This is a work to be fruitfully compared with Steve Fuller's (2000) ground-breaking book on similar themes.

\section{REFERENCES}

Beltrán, A. 1995. Revolución científica, Renacimiento e bistoria de la ciencia. Madrid: Siglo XXI.

Bird, A. 2000. Thomas Kuhn. Chesham: Acumen.

—. 2002. Kuhn's Wrong Turning. Studies in History and Philosophy of Science 33: 443-463.

-. 2005. Naturalizing Kuhn. Proceedings of the Aristotelian Society 105: 109-127.

—. 2008. Incommensurability Naturalized. In Rethinking Scientific Change and Theory Comparison. L. Soler, H. Sankey and P. Hoyningen-Huene, eds. Berlin: Springer: 21-39.

Boyer, C. B. 1959. Commentary on the Papers of Thomas S. Kuhn and I. Bernard Cohen. In Clagett, ed. (1959).

Buchwald, J. Z., and G. E. Smith. 2001. Incommensurability and the Discontinuity of Evidence. Perspectives on Science 9: 463-498.

Butterfield, H. 1931. The Whig Interpretation of History. London: G. Bell \& Sons.

-. 1949. The Origins of Modern Science. London: G. Bell \& Sons.

Clagett, M., ed. 1959. Critical Problems in the History of Science. Madison: The University of Wisconsin Press.

Cohen, I. B. 1985. Revolution in Science. Cambridge, Mass.: Harvard University Press.

D'Agostino, F. 2003. Incommensurability and Commensuration. Aldershot: Ashgate.

Field, H. 1973. Theory Change and the Indeterminacy of Reference. The Journal of Pbilosophy 70: 462-481. Reprinted in Field (2001b).

—. 2001a. Postscript [to: Theory Change and the Indeterminacy of Reference]. In Field (2001b).

- 2001b. Truth and the Absence of Fact. Oxford: Oxford University Press.

Friedman, M. 2003. Kuhn and Logical Positivism. In Nickles, ed. (2003).

Fuller, S. 2000. Thomas Kubn. Chicago: The University of Chicago Press.

—. 2002. Social Epistemology, 2nd. ed. Bloomington: Indiana University Press (1st. ed. 1988).

—. 2003. Kuhn vs. Popper. Cambridge: Icon Books.

Gattei, S. 2008. Thomas Kubn's "Linguistic Turn" and the Legacy of Logical Empiricism. Aldershot: Ashgate.

Godfrey-Smith, P. 2003. Theory and Reality. Chicago: The University of Chicago Press.

Gutting, G. 2003. Thomas Kuhn and French Philosophy of Science. In Nickles, ed. (2003).

Hacking, I. 1993. Working in a New World: The Taxonomic Solution. In Horwich, ed. (1993).

Hanson, N. R. 1958. Patterns of Discovery. Cambridge: Cambridge University Press.

Hawkins, D. 1963. Review of The Structure of Scientific Revolutions. American Journal of Physics 31: 554-555.

Hempel, C. G. 1979. Scientific Rationality: Analytic vs. Pragmatic Perspectives. In Rationality Today, T. F. Geraets, ed.. Ottawa: The University of Ottawa Press.

-. 1981. Turns in the Evolution of the Problem of Induction. Synthese 46: 389-404. Reprinted in Hempel (2001).

-. 1983a. Valuation and Objectivity in Science. In Physics, Philosophy and Psychoanalysis: Essays in Honor of Adolf Grünbaum, R. S. Cohen and L. Laudan, eds. Boston: Reidel. Reprinted in Hempel (2001).

—. 1983b. Kuhn and Salmon on Rationality and Theory Choice. The Journal of Philosophy 80: 570-572.

- 2001. The Philosophy of Carl G. Hempel. J. H. Fetzer, ed. Oxford: Oxford University Press.

Hesse, M. 1963. Review of The Structure of Scientific Revolutions. Isis 54: 286-287.

Horwich, P., ed. 1993. World Changes: Thomas Kubn and the Nature of Science. Cambridge, Mass.: The MIT Press.

Hoyningen-Huene, P. 1993. Reconstructing Scientific Revolutions: Thomas S. Kubn's Philosophy of Science. Foreword by T. S. Kuhn. Trans. by A. T. Levine. Chicago: The University of Chicago Press.

Koffka, K. 1935. Principles of Gestalt Psychology. New York: Harcourt, Brace \& World.

Kuhn, T. S. 1949. [Handy Notebook]. Kuhn's handwritten notes from 31 March to 6 July, 1949. TSKP 1.7.

—. 1951. The Quest for Physical Theory. Lowell Lectures, I-VIII. TSKP 3.11. 
- 1957. The Copernican Revolution. Cambridge, Mass.: Harvard University Press.

- 1959. Energy Conservation as an Example of Simultaneous Discovery. In Clagett, ed. (1959). Reprinted in ET.

- 1970. Logic of Discovery or Psychology of Research? In Lakatos and Musgrave, eds. (1970). Reprinted in ET

- 1977. [= ET] The Essential Tension. Chicago: The University of Chicago Press.

- 1983. Rationality and Theory Choice. The Journal of Philosophy 80: 563-570. Reprinted in RSS.

-. 1996. [ = SSR] The Structure of Scientific Revolutions, 3rd. ed. Chicago: The University of Chicago Press (1st. ed. 1962; 2nd. ed. 1970).

- 1999. Remarks on Incommensurability and Translation. In Incommensurability and Translation. R. Rossini Favretti et al., eds. Cheltenham: Edward Elgar.

- 2000. [ = RSS] The Road Since Structure. J. Conant and J. Haugeland, eds. Chicago: The University of Chicago Press.

Lakatos, I., and Musgrave, A., eds. 1970. Criticism and the Growth of Knowledge. Cambridge: Cambridge University Press.

Larvor, B. 2003. Why Did Kuhn's Structure of Scientific Revolutions Cause a Fuss? Studies in History and Philosophy of Science 34: 369-390.

Laudan, L. 1984. Science and Values. Berkeley: University of California Press.

- 1996. Beyond Positivism and Relativism. Boulder, Colorado: Westview Press.

Marcum, J. A. 2005. Thomas Kubn's Revolution. London: Continuum.

Mayer, A.-K. 2000. Setting Up a Discipline: Conflicting Agendas of the Cambridge History of Science Committee, 1936-1950. Studies in History and Philosophy of Science 31: 665-689.

-. 2004. Setting Up a Discipline, II: British History of Science and "The End of Ideology", 1931-1948. Studies in History and Philosophy of Science 35: 41-72.

Mayoral, J. V. 2009. Intensions, Belief and Science: Kuhn's Early Philosophical Outlook (1940-1945). Studies in History and Philosophy of Science 40: 175-184.

Merton, R. K. 1942. The Normative Structure of Science. Reprinted in The Sociology of Science, N. W. Storer, ed. Chicago: The University of Chicago Press, 1973.

Nickles, T., ed. 2003. Thomas Kubn. Cambridge: Cambridge University Press.

Nola, R., and H. Sankey. 2007. Theories of Scientific Method. Chesham: Acumen.

Pompa, L. 1990. Human Nature and Historical Knowledge. Cambridge: Cambridge University Press.

Preston, J. 2008. Kubn's The Structure of Scientific Revolutions. London: Continuum

Psillos, S. 1999. Scientific Realism: How Science Tracks Truth. London: Routledge.

Quine, W. V. 1953. Two Dogmas of Empiricism. In his From a Logical Point of View. Cambridge, Mass.: Harvard University Press, 1980.

—, and J. S. Ullian. 1978. The Web of Belief, 2nd. ed. New York: McGraw-Hill.

Reisch, G. 1991. Did Kuhn Kill Logical Empiricism? Philosophy of Science 58: 264-277.

Rosenthal, S. 2007. C. I. Lewis in Focus. Bloomington: Indiana University Press.

Salmon, W. C. 1983. C. G. Hempel on the Rationality of Science. The Journal of Philosophy 80: 555-562.

-. 2005. Reality and Rationality. P. Dowe and M. Salmon, eds. Oxford: Oxford University Press.

Sankey, H. 1994. The Incommensurability Thesis. Aldershot: Ashgate.

- 2008. Scientific Realism and the Rationality of Science. Aldershot: Ashgate.

Scheffler, I. 1982. Science and Subjectivity, 2nd. ed. Indianapolis: Hackett

Shapere, D. 1964. The Structure of Scientific Revolutions. The Philosophical Review 73: 385-394.

- 1966. Meaning and Scientific Change. In Mind and Cosmos. R. G. Colodny, ed. Pittsburgh: University of Pittsburgh Press.

- 1971. The Paradigm Concept. Science 172: 706-709.

Solís, C. 1994. Razones e intereses. Barcelona: Paidós.

- 2006. "Una revolución del siglo XX". Introduction to La estructura de las revoluciones científicas [3rd. Spanish ed. of SSR, trans. by C. Solís]. Mexico: FCE.

Toulmin, S. 1953. The Philosopby of Science. London: Hutchinson.

- 1961. Foresight and Understanding. London: Hutchinson.

TSKP = Thomas S. Kuhn Papers, 1922-1996. MC 240. Institute Archives and Special Collections. Massachusetts Institute of Technology. Cambridge, Massachusetts. [TSKP X.Y = TSKP, box X, folder Y] 
Watkins, J. W. N. 1970. Against "Normal Science". In Lakatos and Musgrave, eds. (1970).

Werner, H. 1948. Comparative Psychology of Mental Development, Rev. Ed. Foreword by G. W. Allport. New York: International Universities Press.

JUAN V. MAYORAL is assistant professor at the Department of Philosophy of the University of Zaragoza, and was post-doctoral researcher at the Department of History and Philosophy of Science, University of Cambridge. He wrote a dissertation on Thomas S. Kuhn's intellectual development and has published papers on that subject since then.

AdDREss: Departamento de Filosofía, Universidad de Zaragoza, c/ Pedro Cerbuna, 12, 50009 Zaragoza (Spain). E-mail: jmayoral@unizar.es 